DR. NATALIA RIVA (Orcid ID : 0000-0001-8359-4040)

Article type : Original Articles

\title{
Identification of factors affecting tacrolimus trough levels in Latin-American pediatric liver transplant patients
}

Natalia Riva ${ }^{1,2 *}$, Jean-Baptiste Woillard ${ }^{3}$, Maximiliano Distefano ${ }^{4}$, Matias Moragas ${ }^{4}$, Marcelo

Dip $^{5}$, Esteban Halac ${ }^{5}$, Paulo Cáceres Guido ${ }^{1}$, Nieves Licciardone ${ }^{6}$, Andrea Mangano ${ }^{2,4}$, Andrea Bosaleh ${ }^{7}$, María Teresa de Davila ${ }^{7}$, Paula Schaiquevich ${ }^{1,2}$, Oscar Imventarza ${ }^{5}$

1 Unit of Clinical Pharmacokinetics, Hospital de Pediatría JP Garrahan, Buenos Aires, Argentina.

${ }^{2}$ National Scientific and Technical Research Council, CONICET, Buenos Aires, Argentina.

${ }^{3}$ INSERM, Univ. Limoges, Department of Pharmacology and Toxicology CHU Limoges, IPPRITT, U1248, F-87000 Limoges, France.

${ }^{4}$ Laboratory of Cell Biology and Retrovirus, Hospital de Pediatría JP Garrahan, Buenos Aires, Argentina.

${ }^{5}$ Liver Transplant Service, Hospital de Pediatría JP Garrahan, Buenos Aires, Argentina.

${ }^{6}$ Central Laboratory, Hospital de Pediatría JP Garrahan, Buenos Aires, Argentina.

${ }^{7}$ Pathology Service, Hospital de Pediatría JP Garrahan, Buenos Aires, Argentina.

This article has been accepted for publication and undergone full peer review but has not been through the copyediting, typesetting, pagination and proofreading process, which may lead to differences between this version and the Version of Record. Please cite this article as doi: $10.1002 / 1 \mathrm{t} .25495$

This article is protected by copyright. All rights reserved. 
*Corresponding author: Natalia Riva, PhD, Unit of Clinical Pharmacokinetics, Hospital de Pediatría J.P. Garrahan. Combate de los Pozos 1881, C1245AAL, Buenos Aires, Argentina. E-mail: nataliarivahg@gmail.com. Tel.: 54-11-4122-6000 (ext 6532).

Financial support: This work was funded by Instituto Nacional Central Unico Coordinador de Ablacion e Implante (INCUCAI), Ministry of Health, Argentina.

The funder had no role in study design, data collection and analysis, or preparation of the manuscript.

Keywords: Transplantation, Paediatrics, Cytochrome P450, Immunosuppression, Tacrolimus.

\begin{abstract}
Tacrolimus is the milestone in pediatric liver transplant immunosuppression. Despite close monitoring, fluctuations in tacrolimus blood levels affect safety and efficacy of immunosuppressive treatments. Identifying the factors related to the variability in tacrolimus exposure may be helpful in tailoring the dose. The aim of the present study was to characterize the clinical, pharmacological, and genetic variables associated with tacrolimus systemic exposure in pediatric liver transplant patients.

De-novo transplant patients with a survival of more than one month were considered for inclusion and genotyped for CYP3A5. Peri-transplant clinical factors and laboratory covariates, including alanine aminotransferase (ALT), aspartate aminotransferase (AST), hematocrit, and tacrolimus pre-dose steady-state blood concentrations collected $12 \mathrm{~h}$ after tacrolimus dose $(\mathrm{C} 0)$, were recorded retrospectively between one month and two years posttransplant. A linear mixed effect (LME) model was used to assess the association of these
\end{abstract}


factors and the log-transformed tacrolimus dose-normalized C0 ( $\log \mathrm{C} 0 / \mathrm{D})$. Bootstrapping was used to internally validate the final model. External validation was performed in an independent group of patients that matched the original population. The developed LME model described that $\log \mathrm{C} 0 / \mathrm{D}$ increases as time post-transplant and ALT values increase ( $\beta=0.019,95 \% \mathrm{CI}, 0.010-0.028$ and $\beta=0.00030,95 \% \mathrm{CI}, 0.00002-0.00056$, respectively), whereas it is significantly lower in graft CYP3A5-expressers compared to non-expressers $[\beta=$ $-0.349,95 \% \mathrm{CI},-0.631-(-0.062)]$.

Conclusions: Donor CYP3A5 genotype, time post-transplant and, alanine aminotransferase values are associated with tacrolimus disposition between one month and two years posttransplant. A better understanding of tacrolimus exposure is essential to minimize the occurrence of an out-of-range therapeutic window that may lead to adverse drug reactions or acute rejection.

\section{Introduction}

Tacrolimus has become the cornerstone in immunosuppression in pediatric and adult liver transplant recipients to prevent allograft rejection. This calcineurin inhibitor has a narrow therapeutic index and presents large inter- and intra-individual pharmacokinetic variability (1, 2). In order to optimize its efficacy and minimize the occurrence of adverse events, therapeutic drug monitoring (TDM) is regularly performed in clinical practice based on trough concentrations (C0) determined before the next dose of tacrolimus (1). Trough concentrations have been selected as a measure of systemic exposure that correlates with clinical outcome (graft rejection and tacrolimus toxicity) (3). However, C0-based therapeutic ranges in children are defined based on adult clinical data (2), with subsequent empirical adaptation of the doses according to these trough concentrations. 
Although the optimization of immunosuppressive therapies and the improvements in surgical procedures have contributed to longer overall and graft survival in pediatric liver transplantation, clinical issues, such as acute rejection and adverse drug reactions to tacrolimus, confer morbidity and mortality $(1,4)$. Moreover, previous reports have described a significant association between variability in tacrolimus $\mathrm{C} 0$ and the development of acute rejection and adverse drug reactions $(1,5-7)$. Furthermore, other factors including time posttransplant, body weight, hematocrit, age, liver function parameters, and type of graft contribute to its pharmacokinetic variability in pediatric liver transplant patients $(1,8-16)$.

Different polymorphisms of cytochrome P450 enzymes, especially in CYP3A5, affect tacrolimus clearance. This enzyme plays an important role in the metabolism of tacrolimus, and is mainly expressed in liver and intestine. A polymorphism in intron 3 of CYP3A5 (CYP3A5*3 allele) produces an abnormally spliced mRNA with a premature stop codon resulting in the absence of the CYP3A5 enzyme (17). Several studies have described higher tacrolimus trough concentrations in adult patients carrying the CYP3A5*3 allele (nonexpressers) compared to the expressers (CYP3A5*1 carriers) (18-20). In addition, some studies have reported this association in Asian and European pediatric patients (9-12, 21-23). However, the behavior of tacrolimus variability in Latin-American pediatric liver transplant recipients is unknown and reports regarding safety and efficacy of immunosuppressive regimens are scarce (24).

For all mentioned, we aimed to evaluate the impact of donor and recipient genetic polymorphisms in the CYP3A5 enzyme on tacrolimus $\mathrm{C} 0$ and to identify and characterize different clinical and biochemical variables associated with tacrolimus exposure after oral administration in pediatric liver transplant patients between one month and two years after liver transplantation. 


\section{Methods}

This study is a retrospective, single-center cohort study conducted in accordance to the Helsinki Declaration at Hospital de Pediatría JP Garrahan (Buenos Aires, Argentina) after approval by the Institutional Review Board (Protocol \#740). Written informed consent was obtained from parents or guardians.

\section{Study Population}

This study is part of a previous one that aimed to identify peri-transplant predictors of acute rejection and factors related to the risk of tacrolimus adverse drug reactions in pediatric liver transplant patients (6) in the context of the implementation of a new immunosuppressive protocol. Pediatric de-novo liver allograft recipients less than 18 years old at the time of transplantation were included during the period in which the CYP3A5 genotyping technique was available at the Hospital de Pediatría JP Garrahan. Patients included in the present analysis had at least four tacrolimus trough concentrations during the study period. Exclusion criteria included: less than 1 month of post-transplant survival, re-transplantation, combined or multivisceral transplants, interval of administration of tacrolimus other than every $12 \mathrm{~h}$, and inappropriate follow-up or noncompliance, as previously defined (24). In addition, tacrolimus $\mathrm{C} 0$ levels obtained at times at which the patient was receiving simultaneous administration of azoles, macrolides, antiepileptic drugs, and/or calcium channel blockers, were excluded from the analysis. Follow-up data were collected between 1 month posttransplant and 2 years. All data were collected from the medical and nursing records, and a centralized database with restricted access was generated.

This article is protected by copyright. All rights reserved. 


\section{Immunosuppressive therapy}

Tacrolimus (0.1 $\mathrm{mg} / \mathrm{kg} /$ day $)$ was initiated after reperfusion and kidney function normalization, administered in monotherapy with anti-CD25 induction (basiliximab) on day 0 and day 4 , or in combination with corticosteroids and/or mycophenolate mofetil according to kidney and liver function (25), as depicted in Table 1. Concomitant drugs were sulfamethoxazole-trimethoprim, magnesium supplements, omeprazole (in all patients), acyclovir, and additional antibiotics, if needed.

\section{Tacrolimus monitoring}

For the analysis we used retrospective routine therapeutic drug monitoring (whole-blood 12-h tacrolimus C0). Patients were given oral tacrolimus (Prograft®, Astellas Laboratory, Killorglin, Co. Kerry, Ireland) twice daily. Data (tacrolimus doses, C0s, weight) were recorded after 30 days post-transplantation and every day during hospitalization and/or on out-patient visits for 2 years. At all times that a blood sample was obtained for assessment of tacrolimus $\mathrm{C} 0$, a complete blood sample test was performed including liver and renal function tests, hematocrit and hemoglobin levels. Characteristics of the patients enrolled in the study are presented in Table 1.

Tacrolimus trough concentrations were quantified using the chemiluminescent microparticle immunoassay (CMIA) (Architect; Abbott, Chicago, IL). Whole blood quality controls (Lyphochek Whole Blood Immunosuppressant; Bio-Rad, Irvine, CA) were daily assessed for assay acceptance. In addition, specimens were routinely assessed as part of an international proficiency testing program for the external quality control of tacrolimus (26). Total imprecision was less than $8 \%$, and quality control values lied in the range of +/-2SD. Tacrolimus C0 target levels, defined based on adult clinical data (2), were $7-8 \mathrm{ng} / \mathrm{mL}$ in the 
first 6 months, 5-7ng/mL during the next 6 months, and $5 \mathrm{ng} / \mathrm{mL}$ after the first year posttransplant $(27,28)$.

\section{Biochemical, clinical, and genetic factors}

Peri-transplant and post-transplant variables were studied including: demographic features: age, weight at transplant, gender, and primary diagnosis; biochemical values: hematocrit, albumin, serum creatinine, uremia, total bilirubin, liver function markers (aspartate transaminase (AST), alanine transaminase (ALT), alkaline phosphatase (ALP), and gammaglutamyl transpeptidase (GGT) activity); transplant features: type of graft (partial graft from a living or deceased donor vs. a whole graft from a deceased donor), type of donor (deceased vs. living donor), and days post-transplant; clinical status: Epstein bar virus and cytomegalovirus infections; and genotyping: CYP3A $5 * 3$ polymorphism in donors and recipients. CYP3A5 genotyping procedure was previously described (6).

In addition, we registered concomitant immunosuppressive agents such as steroids (at least 30 consecutive days), azathioprine, mycophenolate mofetil, and sirolimus.

\section{Relationship between tacrolimus $\mathrm{CO}$ and predictor parameters}

A linear mixed effect (LME) model was used to investigate the influence of CYP3A5 genotype, pharmacological factors, and clinical and laboratory parameters on log-transformed tacrolimus dose-normalized $\mathrm{C} 0$ concentrations $(\log \mathrm{C} 0 / \mathrm{D})$.

\section{Model development}

The total dataset was randomly split into a model-building and a validation dataset. The model was initiated with the development of the base model in the model-building dataset to select the best structure for random effects. Different structural models were tested (random 
intercept, slope with and without inter-model correlation) and the best model was selected based on the Akaike information criterion (AIC). Both continuous (time post-transplant, hematocrit, AST, ALT, ALP, and GGT activity) and categorical variables (administration of steroids and/or mycophenolate sodium or mofetil, Epstein-Barr virus infection, cytomegalovirus infection, type of donor, type of graft, and CYP3A5*3 polymorphism in donors and recipients) were considered in the analysis.

Covariates associated with a $\mathrm{p}$ value $<0.05$ in the univariate analysis, and were therefore considered clinically relevant and biologically plausible, were included in the multivariate intermediate model. The final model was selected using a backward stepwise process based on the AIC. All statistical analyses and graphs were performed with RStudio Version 0.99.486, 2015, Inc $(29,30)$ using R (R Core Team, 2015), lme4 (31), and nlme (32).

Finally, all assumptions were checked in the final model, including linearity, absence of colinearity, homoscedasticity, normality of residuals, absence of influential data points, and independence (30).

\section{Model evaluation and external validation.}

Once the final model was defined, a bootstrap was used to evaluate the stability and accuracy and to calculate the 2.5-97.5 percentiles of parameter estimates. The median values of the bootstrap parameters were compared to the values of the final model.

The performance of the model was visually assessed by comparing plots of the predicted concentration (Cpred) and the observed concentration (Cobs) to assess for bias (a systematic upward or downward deviation from the line of unity in these plots) and imprecision (a high degree of scatter of data points around the line of unity).

External validation was performed in the validation dataset that matched the data used for model development. The predictive performance of the model was assessed numerically 
through calculation of the mean error (ME), the mean relative error (MRE), and the relative root mean squared error (RMSE) as previously reported (33).

\section{Results}

Overall, 89 patients were considered for inclusion based on the implementation of a new immunosuppressive protocol in 2010 and according to the availability of data as detailed below. Patients were excluded because of a survival shorter than 1 month $(n=5)$, unavailable medical records $(n=4)$, re-transplantation during the first month after surgery $(n=2)$, absence of pharmacokinetic and clinical data $(\mathrm{n}=5)$, absence of genotyping data from donors and/or recipients due to limited amount of DNA or no availability of formalin-fixed paraffin embedded liver tissue $(n=14)$, and non-adherence as previously defined (6) $(n=6)$. Therefore, 53 patients were finally included in the analysis. Demographics, laboratory parameters, and clinical characteristics of the patients included in the building $(n=40)$ and validation $(n=13)$ of the dataset are shown in Table 1.

CYP3A5 polymorphism distribution in both donors and receptors included in this study is reported in Table S1 (Supporting Table 1). The genotype frequencies of the CYP3A5 polymorphism did not deviate from the Hardy-Weinberg equilibrium $(\mathrm{p}>0.5)$ as previously reported (6). According to the report of the Clinical Pharmacogenetics Implementation Consortium (34), the estimated allele frequency of CYP3A5*1 and $* 3$ in our population was similar to that reported for the Latin American cohort of patients analyzed in the mentioned guideline. Specifically, our population showed an allele frequency of 0.254 and 0.746 for the CYP3A5*1 and *3 allele, respectively.

This article is protected by copyright. All rights reserved. 
A base model was built using 824 tacrolimus trough concentrations obtained from the patients included in the model-building group. Random effects were included in the intercept for inter-individual variability and the slope for the effect of time post-transplant with a correlation between them.

Univariate analysis showed a significant linear association between $\log \mathrm{C} 0 / \mathrm{D}$ and ALT values, time post-transplant, total bilirubin values, donor CYP3A5 polymorphism, and Epstein Barr Virus $(\mathrm{EBV})$ infection status $(\mathrm{p}<0.05)$. All covariates significantly related to $\log \mathrm{C} 0 / \mathrm{D}$ are listed in Table 2. The positive associations between $\log \mathrm{C} 0 / \mathrm{D}$ and time post-transplant and ALT are shown in Figure $1 \mathrm{~A}$ and $\mathrm{B}$, respectively. The figures show an increase in $\log \mathrm{C} 0 / \mathrm{D}$ with time post-transplant or with liver dysfunction assessed by ALT. As depicted in Figure 1 C, $\log \mathrm{C} 0 / \mathrm{D}$ was lower in patients with a CYP3A5-expresser graft compared to nonexpressers $(\mathrm{p}<0.05)$. In more detail, Figure 1 D shows the bivariate model of $\log C 0 / \mathrm{D}$ according to time post-transplant and donor CYP3A5 genotype. Patients with CYP3A5 nonexpresser grafts presented significantly higher $\log \mathrm{C} 0 / \mathrm{D}$ compared to CYP3A5 expressers between one month and two years post transplantation.

After backwards elimination, the best multivariate model describing tacrolimus exposure retained the following covariates that independently correlate with $\log \mathrm{C} 0 / \mathrm{D}$ : time posttransplantation, alanine aminotransferase values and donor CYP3A5 expression. Table 3 summarizes the final model estimates. Visual inspection of residual plots did not reveal any obvious deviations from homoscedasticity or normality (Supporting Figure S1). The predicted concentrations as a function of the observed concentrations of tacrolimus showed that the model performed well in terms of fitness of the data (Figure 2).

This article is protected by copyright. All rights reserved. 
The internal validation of the final model by bootstrapping (1000 successful runs) gave satisfactory results as shown in Table 3. Moreover, in the external validation, the predictive performance of the final model was successfully assessed: the mean error (ME) was 0.213, the mean relative error (MRE) was $2.05 \%$, and precision, expressed as the relative root mean squared error (RMSE) was $15.4 \%$ for the predictive model.

\section{Discussion}

In this study, for the first time in a Latin-American pediatric liver transplant population, we identified different factors that significantly influence tacrolimus exposure. We developed and validated a model that showed a positive association between log-transformed tacrolimus dose-normalized trough concentrations and ALT values as well as time post-transplant, while a negative association with donor CYP3A5 expression (expressers vs. non-expressers) was found between 1 month and 2 years post-transplantation.

Liver function tests, ALT and AST, are traditional markers of acute liver damage secondary to different events including acute rejection episodes, viral infections, and/or liver fibrosis (35). As $98-99 \%$ of tacrolimus is metabolized in the liver (36), it is expected that tacrolimus $\mathrm{C} 0$ increases with liver dysfunction. Previously, apparent clearance was found to decrease exponentially with the increase of AST in adult transplant patients (35). In our study, elevated ALT levels, compatible with impaired liver function, positively correlated with $\log \mathrm{C} 0 / \mathrm{D}$ due to a deficit in tacrolimus metabolism.

Few studies have detected a relationship between tacrolimus exposure and time posttransplant $(11,16)$. In our case, we observed that time post-transplant was retained in the final model and the ratio $\log \mathrm{C} / \mathrm{D}$ increased with time, in line with a reduction in tacrolimus doses (data not shown). In adult transplant patients, reduced tacrolimus dose requirements have been routinely found in the first year after transplantation (37-39). This observation may be 
explained by a decrease in tacrolimus clearance due to drug-drug interactions, increased bioavailability over time, or both $(12,40)$. Regarding drug-drug interactions, introduction or discontinuation of steroids may play an important role. The concurrent use of tacrolimus with mild CYP3A inducers, such as prednisone, may result in decreased tacrolimus trough concentrations whereas the discontinuation of steroids may result in an increased tacrolimus exposure (41). In our study, we registered the administration of steroids in the immunosuppressive maintenance treatment. We tested for the significance of concomitant steroids in tacrolimus $\log \mathrm{C} 0 / \mathrm{D}$ but it was not retained in the final model $(\mathrm{p}>0.05$, Table 3$)$. Thus, we were not able to confirm a drug-drug interaction effect of steroids in tacrolimus pharmacokinetics over time. On the other hand, tacrolimus largely binds to red blood cells and plasma proteins. Thus, the increase over time in oral bioavailability may potentially be due to an increased hematocrit and albumin concentration $(10,12,42)$. In our study, we tested for the significance of hematocrit in tacrolimus $\mathrm{C} 0$ and did not find a significant relation ( $p>0.05$, Table 2) to confirm the change of tacrolimus clearance over time. Nevertheless, the mechanisms responsible for the change in apparent clearance over time are only partly known (38-40) and further studies are required (12).

The metabolism of tacrolimus largely occurs in the liver. CYP3A5 plays a more dominant role in the metabolism of tacrolimus than CYP3A4 (43) and has a significant effect on tacrolimus pharmacokinetics in adult and pediatric transplant patients $(10-12,18,21,22,44$, 45). Specifically in liver transplantation, it has been reported that donor CYP3A5 genotype has a more dominant effect than the recipient genotype on tacrolimus pharmacokinetics $(10$, $11,18,21,22,45)$. This result implies that after day 30 post-transplant, recipients of a graft expressing CYP3A5 have a lower logC0/D compared to recipients of a non-expresser graft. Therefore, higher tacrolimus doses are required in patients with grafts carrying CYP3A5*1 allele compared to non-expressers $(\mathrm{CYP} 3 \mathrm{~A} 5 * 3)$ to achieve the target $\mathrm{C} 0$ according to time 
post transplantation. In these cases, therapeutic drug monitoring is performed as a tool to aid tacrolimus titration until reaching the target range. In agreement with our results, others reported that donor CYP3A5 expression significantly decreased tacrolimus C0/D due to a $30 \%$ increase in tacrolimus clearance in a Japanese pediatric liver transplant population (11) and that tacrolimus daily dose requirement was higher among French children who received a liver expressing CYP3A5 compared with those with a CYP3A5*3 liver (21). The association between donor CYP3A5 genotype and tacrolimus disposition was also reported specifically on the first day after transplantation pediatric liver (46). On the other hand, considering the effect of the recipient CYP3A5-expression stratification we observed no association with tacrolimus exposure in our cohort of patients. However, previous studies in different populations did describe this association. In this sense Caucasian pediatric liver transplant recipients with CYP3A5 expression presented with an increased apparent clearance of tacrolimus compared with non-expressers (12). Furthermore, studies in Chinese pediatric liver transplant patients reported that CYP3A5 genotyping both in recipients and donors was necessary to establish a personalized tacrolimus dosage regimen (22). Therefore, donor genotype in addition to the patient genotype may play an important role in determining the tacrolimus pharmacokinetic response but results varied among studied populations. This highlights the necessity of further studies on the relationship between tacrolimus exposure and pharmacogenetics in both donors and liver pediatric transplant recipients.

Some covariates identified as influential on tacrolimus pharmacokinetics were not retained in our final model. One of the most important pharmacokinetic properties of tacrolimus is its high binding capacity to red blood cells. Several pharmacokinetic studies have reported a significant effect of hematocrit on tacrolimus dose requirements $(10,14)$. This effect was not observed in the present population, which may be explained in part by the partial recovery of hematocrit levels after the first month post-transplant during which considerable variation in 
hematocrit is observed and multiple transfusions are required. The type of donor (living donor/deceased donor) was tested for potential significant association to tacrolimus C0 based on a potential impact of regeneration of the graft (liver) leading to improvement of hepatic function(47). Nonetheless, this variable was not significantly associated with tacrolimus exposure measured as $\mathrm{C} 0$ as shown in Table 2.

There are some limitations to be acknowledged in this study. First, because of its retrospective nature, it has all the limitations inherent to this type of descriptive study. Second, the area under the blood concentration-time curve (AUC) is expected to be a better marker of systemic exposure to tacrolimus than C0 (2); however, the AUC is difficult to obtain due to practical and ethical reasons in the pediatric population. Nevertheless, in children tacrolimus TDM is based on monitoring $\mathrm{C} 0$. Therefore, our results should be interpreted with caution. Third, we focused on the period after 30 days post-transplant in order to avoid the variability produced by hemodynamic alterations, interruption of doses, and different frequency intervals of tacrolimus administration. Finally, we also acknowledge that one of the reasons of the limited number of studied patients was the discontinuation of the genotyping technique due to reagents unavailability.

The starting dose of tacrolimus is usually based on bodyweight and then adjusted by means of therapeutic drug monitoring. Recently, a model was developed to predict the individual starting dose of tacrolimus in pediatric renal transplantation and the final model included bodyweight (48). However, limited information is available in pediatric liver transplant patients. Therefore, our study provides novel information about tacrolimus dosing based on body weight in children with liver transplant.

This article is protected by copyright. All rights reserved. 
After external validation, this model could be used in clinical practice to make dosage recommendations accounting for the liver enzyme levels (ALT), genetics, and time posttransplant-dependent change in the log-C0/D of tacrolimus. For instance, we may assume two random patients in our study population with a body weight of $16.3 \mathrm{~kg}$. The ALT level (UI/L) of Patient 1 is 1200 who underwent liver transplant 3.3 months before, whereas the ALT level in Patient 2 is $40 \mathrm{UI} / \mathrm{L}$ after receiving a liver transplant 9.3 months earlier. None of them is a graft expresser of CYP3A5. If tacrolimus trough concentrations have to be maintained at $5 \mathrm{ng} / \mathrm{ml}$, we could use the present model to calculate the tacrolimus doses. According to our model, the calculated dose for the first child would be $0.35 \mathrm{mg}$ bid, while for the second child it would be $1.11 \mathrm{mg}$ bid. This is in line with a setting in which lower tacrolimus doses are recommended in liver dysfunction to avoid systemic accumulation. If both patients have ALT levels of $40 \mathrm{UI} / \mathrm{L}$, underwent surgery 4 months previously, and Patient 1 has a non-expresser graft while Patient 2 has an expresser graft, tacrolimus doses would be $0.6 \mathrm{mg}$ bid and $1.7 \mathrm{mg}$ bid, respectively.

In conclusion, in the present report we have developed a model to describe tacrolimus pharmacokinetics in children who underwent liver transplantation. This final LME model presented a suitable performance and predictive ability to adequate tacrolimus doses in future patients in order to minimize the occurrence of an out-of-range therapeutic window that may lead to adverse drug reactions or acute rejection. The results of this study may be used in the clinical setting in conjunction with therapeutic drug monitoring and may contribute to the development of programs to optimize tacrolimus dosing, taking into account not only patient body weight but also time post-transplant, genotype, and liver function.

\section{Competing Interests}

There are no competing interests to declare.

This article is protected by copyright. All rights reserved. 


\section{References}

1. Staatz CE, Tett SE. Clinical pharmacokinetics and pharmacodynamics of tacrolimus in solid organ transplantation. Clinical pharmacokinetics. 2004;43(10):623-53.

2. Wallemacq P, Armstrong VW, Brunet M, Haufroid V, Holt DW, Johnston A, et al. Opportunities to optimize tacrolimus therapy in solid organ transplantation: report of the European consensus conference. Therapeutic drug monitoring. 2009;31(2):139-52.

3. Ensor CR, Iasella CJ, Harrigan KM, Morrell MR, Moore CA, Shigemura N, et al. Increasing tacrolimus time-in-therapeutic range is associated with superior one-year outcomes in lung transplant recipients. Am J Transplant. 2018;18:1527-1533.

4. Otte JB. Pediatric liver transplantation: Personal perspectives on historical achievements and future challenges. Liver transplantation : official publication of the American Association for the Study of Liver Diseases and the International Liver Transplantation Society. 2016;22(9):1284-94.

5. Pollock-Barziv SM, Finkelstein Y, Manlhiot C, Dipchand AI, Hebert D, Ng VL, et al. Variability in tacrolimus blood levels increases the risk of late rejection and graft loss after solid organ transplantation in older children. Pediatric transplantation. 2010;14(8):968-75.

6. Riva N, Dip M, Halac E, Caceres Guido P, Woillard JB, Licciardone N, et al. Survival Time to Biopsy-Proven Acute Rejection and Tacrolimus Adverse Drug Reactions in Pediatric Liver Transplantation. Therapeutic drug monitoring. 2018;40(4):401-10.

7. Leino AD, King EC, Jiang W, Vinks AA, Klawitter J, Christians U, et al. Assessment of Tacrolimus Intra-patient Variability in Stable Adherent Transplant Recipients: Establishing Baseline Values. American journal of transplantation : official journal of the American Society of Transplantation and the American Society of Transplant Surgeons. 2018.

This article is protected by copyright. All rights reserved. 
8. Staatz CE, Goodman LK, Tett SE. Effect of CYP3A and ABCB1 single nucleotide polymorphisms on the pharmacokinetics and pharmacodynamics of calcineurin inhibitors: Part i. Clinical pharmacokinetics. 2010;49(3):141-75.

9. De Wildt SN, Van Schaik RHN, Soldin OP, Soldin SJ, Brojeni PY, Van Der Heiden IP, et al. The interactions of age, genetics, and disease severity on tacrolimus dosing requirements after pediatric kidney and liver transplantation. Eur J Clin Pharmacol. 2011;67(12):1231-41.

10. Guy-Viterbo V, Scohy A, Verbeeck RK, Reding R, Wallemacq P, Musuamba FT. Population pharmacokinetic analysis of tacrolimus in the first year after pediatric liver transplantation. Eur J Clin Pharmacol. 2013;69(8):1533-42.

11. Fukudo M, Yano I, Masuda S, Goto M, Uesugi M, Katsura T, et al. Population pharmacokinetic and pharmacogenomic analysis of tacrolimus in pediatric living-donor liver transplant recipients. Clin Pharmacol Ther. 2006;80(4):331-45.

12. Abdel Jalil MH, Hawwa AF, McKiernan PJ, Shields MD, McElnay JC. Population pharmacokinetic and pharmacogenetic analysis of tacrolimus in paediatric liver transplant patients. Br J Clin Pharmacol. 2014;77(1):130-40.

13. Yang JW, Liao SS, Zhu LQ, Zhao Y, Zhang Y, Sun XY, et al. Population pharmacokinetic analysis of tacrolimus early after Chinese pediatric liver transplantation. Int J Clin Pharmacol Ther. 2015;53(1):75-83.

14. Musuamba FT, Guy-Viterbo V, Reding R, Verbeeck RK, Wallemacq P. Population pharmacokinetic analysis of tacrolimus early after pediatric liver transplantation. Therapeutic drug monitoring. 2014;36(1):54-61.

15. Sam WJ, Aw M, Quak SH, Lim SM, Charles BG, Chan SY, et al. Population pharmacokinetics of tacrolimus in Asian paediatric liver transplant patients. $\mathrm{Br} \mathrm{J}$ Clin Pharmacol. 2000;50(6):531-41.

This article is protected by copyright. All rights reserved. 
16. Wallin JE, Bergstrand M, Wilczek HE, Nydert PS, Karlsson MO, Staatz CE. Population pharmacokinetics of tacrolimus in pediatric liver transplantation: early posttransplantation clearance. Therapeutic drug monitoring. 2011;33(6):663-72.

17. Kuehl P, Zhang J, Lin Y, Lamba J, Assem M, Schuetz J, et al. Sequence diversity in CYP3A promoters and characterization of the genetic basis of polymorphic CYP3A5 expression. Nature genetics. 2001;27(4):383-91.

18. Debette-Gratien M, Woillard JB, Picard N, Sebagh M, Loustaud-Ratti V, Sautereau D, et al. Influence of Donor and Recipient CYP3A4, CYP3A5, and ABCB1 Genotypes on Clinical Outcomes and Nephrotoxicity in Liver Transplant Recipients. Transplantation. 2016;100(10):2129-37.

19. Quteineh L, Verstuyft C, Furlan V, Durrbach A, Letierce A, Ferlicot S, et al. Influence of CYP3A5 genetic polymorphism on tacrolimus daily dose requirements and acute rejection in renal graft recipients. Basic Clin Pharmacol Toxicol. 2008;103(6):546-52.

20. Goto M, Masuda S, Kiuchi T, Ogura Y, Oike F, Okuda M, et al. CYP3A5*1-carrying graft liver reduces the concentration/oral dose ratio of tacrolimus in recipients of living-donor liver transplantation. Pharmacogenetics. 2004;14(7):471-8.

21. Durand P, Debray D, Kolaci M, Bouligand J, Furlan V, Fabre M, et al. Tacrolimus dose requirement in pediatric liver transplantation: Influence of CYP3A5 gene polymorphism. Pharmacogenomics. 2013;14(9):1017-25.

22. Chen YK, Han LZ, Xue F, Shen CH, Lu J, Yang TH, et al. Personalized tacrolimus dose requirement by $\mathrm{CYP} 3 \mathrm{~A} 5$ but not $\mathrm{ABCB} 1$ or $\mathrm{ACE}$ genotyping in both recipient and donor after pediatric liver transplantation. PLoS One. 2014;9(10):e109464.

23. Min S, Papaz T, Lafreniere-Roula M, Nalli N, Grasemann H, Schwartz SM, et al. A randomized clinical trial of age and genotype-guided tacrolimus dosing after pediatric solid organ transplantation. Pediatric transplantation. 2018;22(7):e13285.

This article is protected by copyright. All rights reserved. 
24. Riva N, Schaiquevich P, Caceres Guido P, Halac E, Dip M, Imventarza O. Pharmacoepidemiology of tacrolimus in pediatric liver transplantation. Pediatric transplantation. 2017;21(5).

25. Kelly DA. Current issues in pediatric transplantation. Pediatric transplantation. 2006;10(6):712-20.

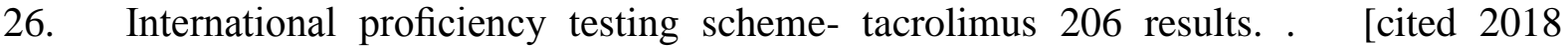
December]; Available from: http://www.bioanalytics.co.uk/Tacrolimus\%20Front\%20Pages/tacro206.pdf 27. Weber LT, Dotsch J. Therapeutic monitoring of immunosuppressive drugs in pediatric patients: special considerations. Expert Rev Clin Pharmacol. 2016;9(8):1001-3.

28. Dell-Olio D, Kelly DA. Calcineurin inhibitor minimization in pediatric liver allograft recipients. Pediatric transplantation. 2009;13(6):670-81.

29. Team RC. R: A language and environment for statistical computing. R Foundation for Statistical Computing. 2016 [cited; Available from: https://www.R-project.org/

30. Winter B. Linear models and linear mixed effects models in $\mathrm{R}$ with linguistic applications. 2013 [cited 2018; Available from: http://arxiv.org/pdf/1308.5499.pdf

31. Douglas Bates MM, Ben Bolker, Steve Walker. Fitting Linear Mixed-Effects Models Using lme4. Journal of Statistical Software. 2015;67(1):1-48.

32. Pinheiro J BD, DebRoy S, Sarkar D and R Core Team. nlme: Linear and Nonlinear Mixed Effects Models. 2017 [cited 2018; Available from: https://CRAN.Rproject.org/package $=$ nlme

33. Bloomfield C, Staatz CE, Unwin S, Hennig S. Assessing Predictive Performance of Published Population Pharmacokinetic Models of Intravenous Tobramycin in Pediatric Patients. Antimicrob Agents Chemother. 2016;60(6):3407-14. 
34. Birdwell KA, Decker B, Barbarino JM, Peterson JF, Stein CM, Sadee W, et al. Clinical Pharmacogenetics Implementation Consortium (CPIC) Guidelines for CYP3A5 Genotype and Tacrolimus Dosing. Clin Pharmacol Ther. 2015;98(1):19-24.

35. Staatz CE, Willis C, Taylor PJ, Tett SE. Population pharmacokinetics of tacrolimus in adult kidney transplant recipients. Clin Pharmacol Ther. 2002;72(6):660-9.

36. Venkataramanan R, Jain A, Warty VW. Pharmacokinetics of FK 506 following oral administration: a comparison of FK 506 and cyclosporine. Transplant Proc. 1991 Feb;23:931-3.

37. Pou L, Brunet M, Andres I, Rodamilans M, Lopez R, Corbella J. Influence of posttransplant time on dose and concentration of tacrolimus in liver transplant patients. Transpl Int. 1998;11 Suppl 1:S270-1.

38. Christiaans M, van Duijnhoven E, Beysens T, Undre N, Schafer A, van Hooff J. Effect of breakfast on the oral bioavailability of tacrolimus and changes in pharmacokinetics at different times posttransplant in renal transplant recipients. Transplantation proceedings. 1998;30(4):1271-3.

39. Saint-Marcoux F, Woillard JB, Jurado C, Marquet P. Lessons from routine dose adjustment of tacrolimus in renal transplant patients based on global exposure. Therapeutic drug monitoring. 2013;35(3):322-7.

40. Woillard JB, Saint-Marcoux F, Debord J, Asberg A. Pharmacokinetic models to assist the prescriber in choosing the best tacrolimus dose. Pharmacol Res. 2018;130:316-21.

41. Micromedex-Solutions. Tacrolimus. Truven Health Analytics 2018. [cited 2018 19th December]; Available from: http://www.micromedexsolutions.com

42. Garcia Sanchez MJ, Manzanares C, Santos-Buelga D, Blazquez A, Manzanares J, Urruzuno P, et al. Covariate effects on the apparent clearance of tacrolimus in paediatric liver 
transplant patients undergoing conversion therapy. Clinical pharmacokinetics. 2001;40(1):6371.

43. Dai Y, Hebert MF, Isoherranen N, Davis CL, Marsh C, Shen DD, et al. Effect of CYP3A5 polymorphism on tacrolimus metabolic clearance in vitro. Drug metabolism and disposition: the biological fate of chemicals. 2006;34(5):836-47.

44. Hesselink DA, Bouamar R, Elens L, van Schaik RH, van Gelder T. The role of pharmacogenetics in the disposition of and response to tacrolimus in solid organ transplantation. Clinical pharmacokinetics. 2014;53(2):123-39.

45. Buendia JA, Bramuglia G, Staatz CE. Effects of combinational cyp3a5 6986a>g polymorphism in graft liver and native intestine on the pharmacokinetics of tacrolimus in liver transplant patients: A meta-analysis. Therapeutic drug monitoring. 2014;36(4):442-7.

46. Calvo PL, Serpe L, Brunati A, Nonnato A, Bongioanni D, Olio DD, et al. Donor CYP3A5 genotype influences tacrolimus disposition on the first day after paediatric liver transplantation. Br J Clin Pharmacol. 2017;83(6):1252-62.

47. Campagne O, Mager DE, Tornatore KM. Population Pharmacokinetics of Tacrolimus in Transplant Recipients: What Did We Learn About Sources of Interindividual Variabilities? Journal of clinical pharmacology. 2019;59(3):309-25.

48. Andrews LM, Hesselink DA, van Gelder T, Koch BCP, Cornelissen EAM, Bruggemann RJM, et al. A Population Pharmacokinetic Model to Predict the Individual Starting Dose of Tacrolimus Following Pediatric Renal Transplantation. Clinical pharmacokinetics. 2018;57(4):475-89.

This article is protected by copyright. All rights reserved. 


\section{Figure legends}

Figure 1. Relation between Log-transformed dose normalized tacrolimus trough concentrations according to time post-transplantation (A), alanine aminotransferase values (B), and donor CYP3A5 genotype (C). Bivariate linear mixed effect model according to time post-transplant and donor CYP3A5 genotype.

$* \mathrm{p}<0.05$

Abbreviations: ALT: alanine aminotransferase; C0: tacrolimus trough concentrations; CYP3A5: donor CYP3A5 genotype (0: non-expressers, 1:expressers).

Figure 2. Goodness of fit plot of the final model. Observed vs. individual predicted tacrolimus concentrations.

Abbreviations: $\mathrm{C} 0$ : tacrolimus trough concentrations (ng/ml); D: single tacrolimus dose $(\mathrm{mg} / \mathrm{kg})$.

\section{Supporting information.}

Supporting Figure S1. Plots of the standardized residuals versus fitted values (A), histogram of residuals (B) and quartile-quartile plots (QQ-plots) (C). 
Table 1. Demographics and relevant medical history

\begin{tabular}{|c|c|c|}
\hline Characteristics/Parameters & $\begin{array}{l}\text { Model-building } \\
\text { Data Set }\end{array}$ & $\begin{array}{l}\text { Validation } \\
\text { Data Set }\end{array}$ \\
\hline Number of subjects & 40 & 13 \\
\hline Age (years) $\dagger \mathbb{I}$ & $2.2(0.5-17.6)$ & $3.7(0.8-12.2)$ \\
\hline Sex (female/male) & $24 / 16$ & $10 / 3$ \\
\hline Weight $(\mathrm{kg}) \dagger \mathbb{I}$ & $16.3(6.0-75.0)$ & $19(6.8-74)$ \\
\hline Type of donor (deceased/living) & $31 / 9$ & $10 / 3$ \\
\hline Follow-up time (months) $\dagger \mathbb{I}$ & $18.6(1.3-25.9)$ & $18.6(1.4-30.9)$ \\
\hline Graft type (complete/technical variant) & $17 / 23$ & $2 / 11$ \\
\hline Primary Diagnosis & Number $(\%)$ & \\
\hline Biliary atresia & $16(40)$ & $6(46)$ \\
\hline Acute liver failure & $9(23)$ & $2(15)$ \\
\hline Cholestatic cirrhosis & $4(10)$ & $3(23)$ \\
\hline $\begin{array}{l}\text { Hepatic cirrhosis: autoimmune and } \\
\text { cryptogenic }\end{array}$ & $6(15)$ & $1(8)$ \\
\hline Malignancies§ & $3(7)$ & $1(8)$ \\
\hline Metabolic disease: metabolic liver failure & $2(5)$ & $0(0)$ \\
\hline \multicolumn{3}{|l|}{ Immunosuppressive therapy } \\
\hline $\begin{array}{l}\text { Basiliximab ( } 10 \text { to } 20 \mathrm{mg} / \mathrm{doses} \text { at days } 0 \text { and } \\
4 \text { after transplantation) }\end{array}$ & $28(70)$ & $10(77)$ \\
\hline Tacrolimus (0.1 mg/kg/day) & $40(100)$ & $13(100)$ \\
\hline Prednisone (1.25-3.75 mg/kg/day) & $35(88)$ & $11(86)$ \\
\hline Mycophenolate mofetil (20-40 mg/kg/day) & $20(50)$ & $7(54)$ \\
\hline Azathioprine (1-2 mg/kg/day) & $3(8)$ & $2(15)$ \\
\hline Sirolimus $(0.1 \mathrm{mg} / \mathrm{kg} /$ day $)$ & $4(10)$ & $1(8)$ \\
\hline Liver function and blood parametersI & Mean (SD) & \\
\hline AST (UI/L) & $88.8(120.5)$ & $82.3(100.9)$ \\
\hline ALT (UI/L) & $135.1(153.3)$ & $120.6(139.2)$ \\
\hline GGT (UI/L) & $234.0(305.4)$ & $295.4(346.4)$ \\
\hline Total bilirubin (mg/dL) & $2.3(1.8)$ & $2.3(4.5)$ \\
\hline Direct bilirubin (mg/dL) & $0.9(2.2)$ & $2.3(4.8)$ \\
\hline $\operatorname{Albumin}(\mathrm{g} / \mathrm{dL})$ & $3.6(0.6)$ & $3.4(0.6)$ \\
\hline Hematocrit (\%) & $32.7(4.6)$ & $32.8(5.1)$ \\
\hline Serum creatinine $(\mathrm{mg} / \mathrm{dL})$ & $0.4(0.2)$ & $0.5(0.2)$ \\
\hline Pharmacokinetic data II & Mean (SD) & \\
\hline Total number of tacrolimus samples & 824 & 352 \\
\hline Number of samples per patient $\dagger$ & $16(4-71)$ & $29(4-48)$ \\
\hline Tacrolimus blood concentrations (ng/ml) & $6.3(2.6)$ & $6.8(2.7)$ \\
\hline Tacrolimus daily dose (mg) & $2.6(2.1)$ & $2.9(2.3)$ \\
\hline Tacrolimus daily dose normalized $(\mathrm{mg} / \mathrm{kg})$ & $0.15(0.10)$ & $0.14(0.10)$ \\
\hline $\begin{array}{l}\text { Dose normalized tacrolimus trough } \\
\text { concentration }[(\mathrm{ng} / \mathrm{ml}) /(\mathrm{mg} / \mathrm{kg})]\end{array}$ & $114.39(96.99)$ & $149.27(122.75)$ \\
\hline $\begin{array}{l}\text { Log-transformed dose normalized tacrolimus } \\
\text { trough concentration }\end{array}$ & $4.50(0.68)$ & $4.70(0.80)$ \\
\hline
\end{tabular}

This article is protected by copyright. All rights reserved. 
Abbreviations: AST, aspartate aminotransferase; ALT, alanine transaminase; GGT, gammaglutamyl transpeptidase.

$\dagger$ Data are expressed as median (range). $\$$ Including Alagille syndrome, congenital hepatic fibrosis, and sclerosing cholangitis. §Including hepatoblastoma and hepatocellular carcinoma. II Continuous demographic data and clinical laboratory data recorded during the complete study period did not significantly differ between model-building and validation data sets (Mann-Whitney U test, $\mathrm{p}>0.05$ ).

Table 2. Univariate linear mixed models for the log-transformed dose-normalized tacrolimus trough concentrations in pediatric liver transplant patients

\begin{tabular}{llll}
\hline Variables & Estimate $(\beta)$ & $\begin{array}{l}\text { Standard } \\
\text { error }\end{array}$ & p-value \\
\hline Laboratory parameters & & & \\
\hline ALT (UI/L) & 0.0005 & 0.0001 & $<0.001$ \\
Hematocrit (\%) & -0.0005 & 0.0043 & 0.90 \\
Total bilirubin (mg/dL) & 0.032 & 0.012 & 0.01 \\
\hline Immunosuppressive scheme & & \\
\hline Co-administration of steroids and/or & & \\
Mycophenolate mofetil/sodium (yes vs no) & 0.115 & 0.043 & 0.01 \\
\hline Clinical parameters & & & \\
CMV infection (yes vs no) & -0.094 & 0.095 & 0.33 \\
EBV infection (yes vs no) & -0.152 & 0.061 & 0.01 \\
Time post-transplant (months) & 0.023 & 0.004 & $<0.001$ \\
\hline Transplant variables & & & \\
\hline Type of donor (living vs deceased) & -0.163 & 0.207 & 0.44 \\
Graft type (complete=1 vs technical variant=0) & 0.143 & 0.171 & 0.41 \\
\hline $\begin{array}{l}\text { Genetic variables } \\
\text { Donor CYP3A5 polymorphism (expressers vs } \\
\text { non-expressers) }\end{array}$ & & \\
\hline
\end{tabular}

Abbreviations: ALT: alanine aminotransferase; CMV: cytomegalovirus; EBV: Epstein Barr Virus.

This article is protected by copyright. All rights reserved. 
Table 3. Parameter estimates of the final linear mixed effects model and bootstrap results.

\begin{tabular}{|c|c|c|c|}
\hline $\begin{array}{l}\text { Parameters (units) } \\
\text { Fixed effects }\end{array}$ & Estimates (\%SE) & P value & $\begin{array}{l}2.5,97.5 \text { percentiles } \\
\text { of the bootstrap }\end{array}$ \\
\hline (Intercept) & $4.424(10.644)$ & $<0.001$ & $4.186,4.647$ \\
\hline Time post-transplant per month & $0.019(0.437)$ & $<0.001$ & $0.010,0.028$ \\
\hline ALT (UI/L) & $0.00030(0.014)$ & 0.03 & $0.00002,0.00056$ \\
\hline $\begin{array}{l}\text { Donor CYP3A5 polymorphism } \\
\text { (expressers vs non-expressers) }\end{array}$ & $-0.349(13.840)$ & 0.02 & $-0.631,-0.062$ \\
\hline Interaction term (Time*ALT) & $0.00005(0.002)$ & 0.004 & $0.00001,0.00008$ \\
\hline \multicolumn{4}{|l|}{ Random effects } \\
\hline Random effect on subject & 0.580 & & $0.439,0.708$ \\
\hline Random effect on slope & 0.018 & & $0.010,0.025$ \\
\hline Correlation between random effects & -0.852 & & $-1.000,-0.645$ \\
\hline Residual variability & 0.350 & & $0.332,0.369$ \\
\hline
\end{tabular}

Abbreviations: ALT: alanine aminotransferase; SE: Standard error.

A

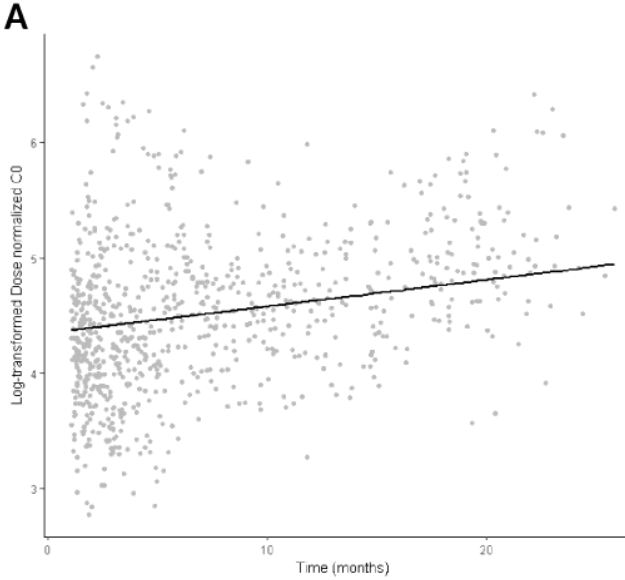

C

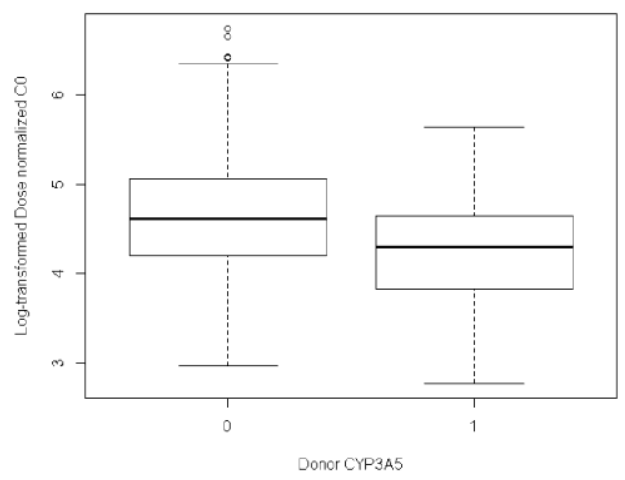

B

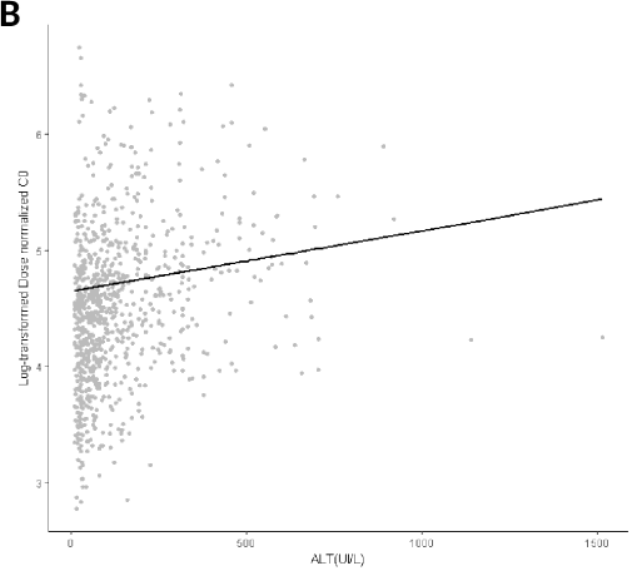

D

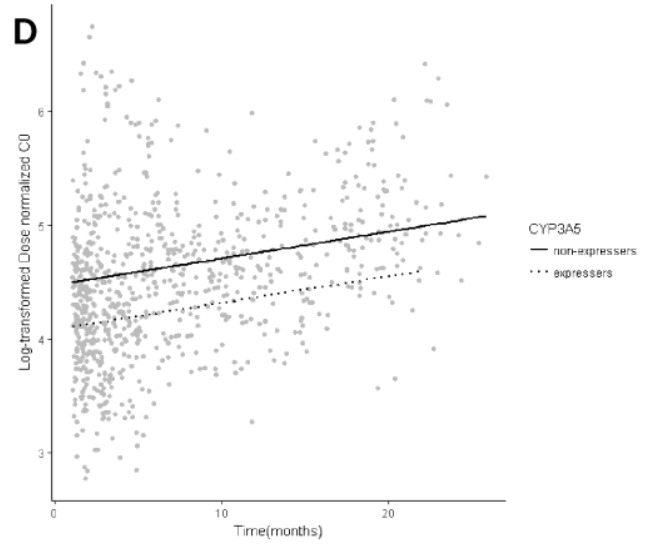

This article is protected by copyright. All rights reserved. 


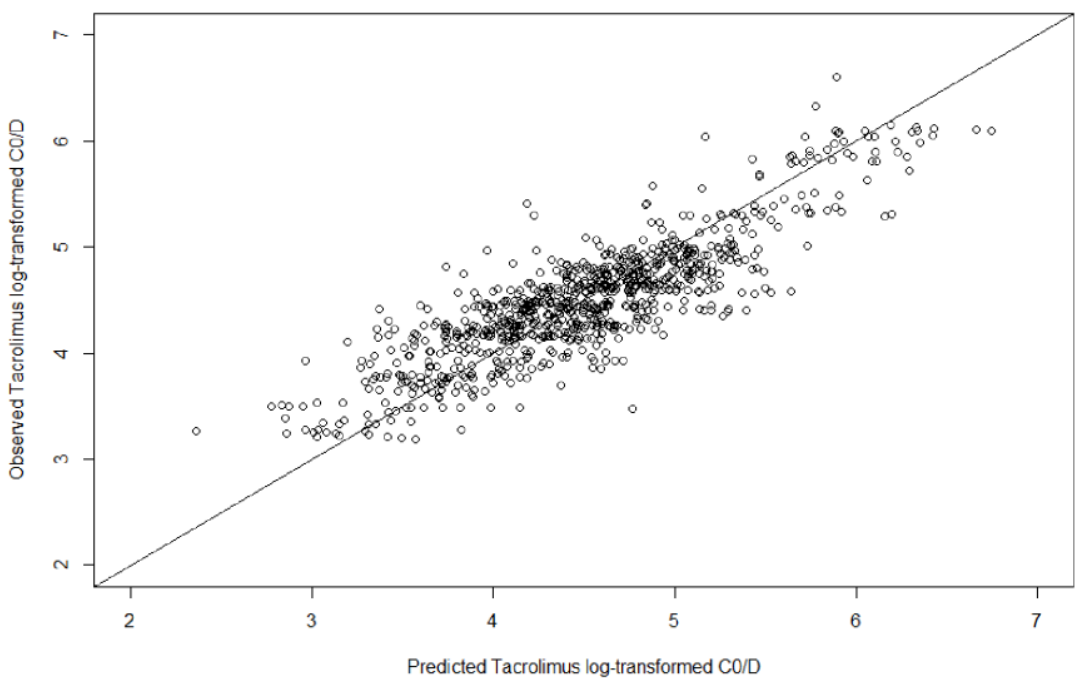

This article is protected by copyright. All rights reserved. 